\title{
FLORESCIMENTO E FRUTIFICAÇÃO DE LICHIEIRAS EM FUNÇÃO DO ANELAMENTO DE RAMOS ${ }^{1}$
}

\author{
ELISEO GARCÍA-PÉREZ² \& ANTONIO BALDO GERALDO MARTINS ${ }^{3}$
}

\begin{abstract}
Resumo - Avaliou-se o efeito do anelamento de ramos sobre o florescimento e frutificação de lichieiras 'Bengal' com 17 anos de idade. Os tratamentos constaram de anelamento em ramos ou pernadas principais e ramos de $6 ; 4$ e $2 \mathrm{~cm}$ de diâmetro, além do controle. O delineamento utilizado foi em blocos casualizados, com cinco repetições. As avaliações quanto à floração foram: percentagem de floração e comprimento de inflorescências por quadrante e árvore; quanto à frutificação, avaliaram-se: vingamento de frutos maduros por panícula, massa, diâmetros longitudinal e equatorial dos frutos, sólidos solúveis totais, época de colheita e rendimento. O anelamento nos ramos principais induziu maior florescimento, sem alterar as características das inflorescências; não houve diferenças no vingamento de frutos, mas o aumento na floração incrementou o rendimento por árvore, com significativa antecipação da colheita.
\end{abstract}

Termos para indexação: Litchi chinensis, pegamento de fruto, produção.

\section{FLOWERING AND FRUITING OF LYCHEE TREES IN RESPONSE TO GIRDLING OF BRANCHES}

Abstract - The effects of girdling of branches on flowering and fruiting of 17 years old 'Bengal' lychee trees were evaluated. The treatments consisted of girdling of main branches, and branches with 6,4 and $2 \mathrm{~cm}$ of diameter and the control. The experiment was conducted in a randomized block design, with 5 replicates. The evaluations in relation to flowering were: flowering per tree and per quadrant and length of flower panicles; in relation to fruiting were: fruit set per panicle, fruit weight, longitudinal and equatorial diameters, soluble solids, harvest time and production. The girdling in the main branches induced larger flowering, without influence on the flower panicles characteristics, there were no differences in the fruit set, but with an increasing in the flowering, it increased the production, with significant anticipation of the harvest.

Index terms: Litchi chinensis, fruit set, production.

\section{INTRODUÇÃO}

A lichieira (Litchi chinensis Sonn.) é originária da região sudeste da China, mais exatamente da província de Guangdong e norte de Vietnã. Atualmente, é cultivada em diferentes áreas subtropicais e tropicais do mundo. Considera-se a cultura como alternante, e, para anos de grande produção, o volume de fruta produzida no mundo está em torno de 2.000.000 de toneladas, sendo China, Vietnã, Tailândia, Índia, Madagascar e África do Sul os principais países produtores (Menzel, 2001;Huang, 20044). A introdução desta espécie, no Brasil, deu-se por volta de 1810, no Jardim Botânico do Rio de Janeiro (Carvalho \& Salomão, 2000). Plantações comerciais ocorreram nas décadas de 70 e 80. Em 1997, foram registrados 347 hectares nos Estados de Minas Gerais, Bahia, Paraná e São Paulo, sendo este último o maior produtor (Yamanishi et al., 2001). Para o ano de 2004, estima-se um aumento de área cultivada em cerca de $188 \%$, num total de 1.000 hectares com lichia no Brasil (Kawati, 20045).

Produções irregulares, associadas à pequena floração e ao baixo pegamento de frutos, são problemas importantes da cultura no mundo. A característica de alternância de produção em diversas cultivares e restrições de ordem climática são as principais causas associadas ao problema de floração (Ghosh, 2001). A lichia requer um período frio, prévio à floração. Existem evidências de que temperaturas noturnas menores de $15^{\circ} \mathrm{C}$ durante outono favorecem a indução floral, e temperaturas diurnas altas no mesmo período reduzem a eficiência das temperaturas baixas (Galán \& Menini, 1987; Menzel \& Simpson, 1995). Quando a cultura está em áreas de clima quente e grande precipitação, como acontece na Flórida-USA, ou na região centro-oeste do Estado de São Paulo, as árvores apresentam surtos vegetativos muito vigorosos, a cada dois ou três meses, em detrimento da floração (Li et al., 2001).

Existem referências da avaliação de diversas técnicas para contornar o problema de baixo florescimento, e o anelamento de ramos tem sido uma das mais promissoras. Na China, avaliaram o anelamento fechado e em espiral, sendo que ambos incrementaram a floração e o rendimento de árvores da cultivar Nuomici. Aumentos nos teores de açúcares solúveis e amido nas folhas também foram constatados (Li \& Xiao, 2001). Sugere-se que o anelamento deva ser feito quando a brotação vegetativa desenvolvida, após a colheita dos frutos, amadurece; na Austrália, é realizado a partir dos últimos dias do mês de março, evitando-se assim novas brotações e permitindo que a gema apical dos brotos maduros seja induzida a florescer. A prática tem o efeito de interromper o fluxo de assimilados que, em condições normais, são utilizados no crescimento de ramos e raízes, porém seu efeito nas plantas, em longo prazo, ainda não é conhecido (Menzel, 2001).

Desta forma, o presente trabalho objetivou avaliar o efeito do anelamento sobre a floração e a frutificação de árvores de lichia 'Bengal' no município de Taquaritinga-SP.

\section{MATERIAL E MÉTODOS}

O experimento foi conduzido durante o período de $04 / 2003$ a 12/2004, na Fazenda Santo Antônio, município de Taquaritinga, Estado de São Paulo, com as coordenadas $21^{\circ} 24^{\prime} \mathrm{S}$; $48^{\circ} 29^{\prime} \mathrm{W}$ e $560 \mathrm{~m}$ de altitude. O clima da região é do tipo Cwa, segundo a classificação de Köppen, com temperatura média mínima de $16.7^{\circ} \mathrm{C}$, temperatura média máxima de $28.8^{\circ} \mathrm{C}$ e uma precipitação total anual de $1.442 \mathrm{~mm}$. Foram utilizadas árvores de lichia da cultivar Bengal, com 17 anos de idade, provenientes de mudas obtidas por alporque e plantadas em espaçamento de 9 × $8 \mathrm{~m}$. Em abril de 2003, foram selecionadas 25 plantas, em função do porte e brotação vegetativa superior a $50 \%$. Os tratamentos foram em plantas individualizadas: $\mathrm{T} 1=$ anelamento de ramos ou pernadas principais $(10$ $-25 \mathrm{~cm}$ de diâmetro); $\mathrm{T} 2=$ anelamento de ramos de $6 \mathrm{~cm}$; $\mathrm{T} 3=$ anelamento de ramos de $4 \mathrm{~cm}$; T4 = anelamento de ramos de $2 \mathrm{~cm}$ de diâmetro, e T5 = testemunha sem anelamento. $\mathrm{O}$ delineamento experimental foi em blocos ao acaso, com cinco repetições, com uma árvore como parcela experimental.

Os tratamentos foram realizados na primeira quinzena do mês

\footnotetext{
(Trabalho 064/2005). Recebido: 15/04/2005. Aceito para publicação: 10/03/2006.

${ }^{2}$ Ing. Agr., MSc., doutorando do Departamento de Produção Vegetal, FCAV-UNESP Campus Jaboticabal, bolsista de CONACYT-Colegio de Postgraduados, México. CEP: 14884-900, Jaboticabal, SP. E-mail: eligarpe05@hotmail.com

${ }^{3}$ Ing. Agr., Dr., Prof. do Departamento de Produção Vegetal, FCAV-UNESP Câmpus Jaboticabal, CEP: 14884-900, Jaboticabal, SP.

${ }^{4}$ HUANG, X. (South Agricultural University Guangzhou, Guangdong Province, China). Comunicação pessoal, 2004.

${ }^{5}$ KAVATI, R. (CATI, DEXTRU- Campinas-SP). Comunicação pessoal, 2004.
} 
de maio, com ajuda da serra de poda e um anelador usado em videira, e a incisão foi de $2,5 \mathrm{~mm}$ a $4 \mathrm{~mm}$ de largura em função do equipamento usado; depois de realizados os cortes, foi passada uma calda à base de cobre como prevenção contra doenças. Para o caso do tratamento em ramos ou pernadas principais, foram anelados todos os ramos presentes, com exceção de dois ou três ramos pequenos que têm a função de manter o fluxo de fotoassimilados. O anelamento foi realizado a $70 \mathrm{~cm}$ do nível do solo para evitar o molhamento dos cortes pelo microaspersor utilizado na irrigação. Os tratamentos em ramos de 6; 4 e $2 \mathrm{~cm}$ de diâmetro foram realizados, respectivamente, em dois, três e quatro ramos por quadrante, em cada árvore.

Foram registradas as temperaturas máximas e mínimas no período do experimento. Os parâmetros avaliados foram: percentagem de floração por quadrante (nordeste (NE), noroeste (NO), sudeste (SE), sudoeste (SO)) e por árvore, que foi determinada visualmente, considerando o volume de ramos anelados por tratamento e o volume da copa com floração por quadrante; e comprimento das inflorescências, medindo-se 20 amostras por quadrante; quanto à frutificação, foram marcadas 20 inflorescências por quadrante para avaliar frutos vingados, massa, diâmetro longitudinal e equatorial de frutos, teor de sólidos solúveis totais, época de colheita e rendimento, que foi estimado em função de cachos por árvore e número médio de frutos por cacho. Os dados foram submetidos à análise de variância, e as médias, comparadas pelo teste de Tukey.

\section{RESULTADOS E DISCUSSÃO}

\section{Temperaturas versus floração}

A lichia cultivar Bengal é considerada como alternante, característica que é mais acentuada quando cultivada em climas quentes, com restrições de temperaturas para favorecer a indução à floração. As temperaturas máxima e mínima registradas nos meses de outono-inverno, para o ano de 2003, que foi de pouca floração, e para 2004, que foi de alta floração, estão registradas na Tabela 1, na qual se observa que não apresentaram grandes diferenças. No entanto, é importante assinalar que, em 2004, houve temperaturas mínimas menores nos meses de março e junho e temperaturas máximas mais amenas nos meses de maio, junho e julho, o que possivelmente seja um indicador da existência de temperaturas mais favoráveis para o maior florescimento. Menzel \& Simpson (1995) encontraram que temperaturas menores de $15^{\circ} \mathrm{C}$, quatro ou seis semanas prévias ao florescimento, são favoráveis à indução floral, e temperaturas muito altas, no mesmo período, podem inibir o efeito das temperaturas baixas favoráveis; é possível que, em 2003, as maiores temperaturas máximas tenham contribuído junto com outros fatores ao menor florescimento, porém é necessário um estudo mais detalhado para entender a interação de temperaturas e de outros fatores sobre a indução da floração.

Foi observada uma resposta diferenciada do florescimento, em função dos quadrantes dentro de cada árvore. Constatou-se que existem diferenças estatísticas entre os quadrantes para a percentagem de florescimento, no ano 2003, e não houve diferenças em 2004 (Tabela 2). As linhas de plantio têm orientação norte(N)-sul(S), com o tamanho atual das árvores, existe sombreamento nos quadrantes $\mathrm{N}$ e $\mathrm{S}$ das
TABELA 1 - Temperaturas máxima e mínima, nos meses de março a agosto, e floração de árvores (testemunha) de lichia 'Bengal', em dois anos. Taquaritinga-SP.

\begin{tabular}{lcccccc}
\hline Meses & $\begin{array}{c}\text { Tmáx } \\
\left({ }^{\circ} \mathbf{C}\right)\end{array}$ & $\begin{array}{c}\text { Tmín } \\
\left({ }^{\circ} \mathbf{C}\right)\end{array}$ & $\begin{array}{c}\text { Floração } \\
(\mathbf{\%})\end{array}$ & $\begin{array}{c}\text { Tmáx } \\
\left({ }^{\circ} \mathbf{C}\right)\end{array}$ & $\begin{array}{c}\text { Tmín } \\
\left({ }^{\circ} \mathbf{C}\right)\end{array}$ & $\begin{array}{c}\text { Floração } \\
(\%)\end{array}$ \\
\hline Março & 30,6 & 19,5 & 33,20 & 30,7 & 18,1 & 67,60 \\
Abril & 29,8 & 17,5 & & 29,7 & 18,1 & \\
Maio & 26,8 & 13,3 & & 25,4 & 14,1 & \\
Junho & 28,8 & 14,4 & & 25,6 & 13,0 & \\
Julho & 27,8 & 12,6 & & 25,3 & 12,5 & \\
Agosto & 28,4 & 12,3 & & 29,5 & 13,3 & \\
\hline
\end{tabular}

árvores, portanto as avaliações foram nos quadrantes NE - NO (mais expostos à luminosidade) e SE e SO (menor exposição). Os resultados indicam que os quadrantes menos expostos à luz apresentam maior florescimento, sobretudo no ano em que, em geral, houve menor florescimento. Maior exposição à luz solar pode gerar maiores temperaturas nas áreas expostas, segundo Menzel \& Simpson (1995), temperaturas altas podem ter efeito inibidor às condições determinantes para indução floral; então é possível que, ao nível dos brotos, estejam acontecendo estas interações, daí as diferenças de florações por orientação avaliada. Evidencia-se também a importância da orientação das linhas no estabelecimento de um pomar e de práticas de manejo, como a poda, para garantir exposição uniforme à luz solar.

\section{Floração}

Para comparar o efeito do anelamento sobre a floração, foi considerada a floração total por árvore, no ano de 2003, em que foram realizados os anelamentos, e em 2004, para observar o efeito residual dos tratamentos. Em 2003, que foi de baixa floração para a cultivar Bengal, verifica-se que houve diferença estatística entre tratamentos (Tabela 3), sendo que o anelamento em ramos principais, com $59 \%$ de floração, foi superior à testemunha e ao tratamento em ramos de $2 \mathrm{~cm}$ de diâmetro, que apresentou a menor floração. Estes resultados são semelhantes aos relatados por Li \& Xiao (2001), que observaram o efeito positivo do anelamento sobre o florescimento. Em 2004, ano de alta floração em geral, houve incremento importante no florescimento em todos os tratamentos, com diferença estatística em favor do tratamento de ramos principais e testemunha. Isto indica que o anelamento, em ramos principais, não interfere com o florescimento num segundo ano. Apesar do efeito na floração, não se observou qualquer influência dos tratamentos nos comprimentos das inflorescências terminal e subterminal.

\section{Frutificação}

Em relação ao total de frutos vingados por inflorescência, não se observou diferença estatística entre tratamentos (Tabela 4), e os ramos com anelamento apresentaram, em média, 20 frutos por inflorescência, o que é considerado como um bom resultado; para a cultivar Bengal, reporta-se uma variação de 1 a 50 frutos por inflorescência (Menzel \& Kernot, 2002). A época de colheita é um parâmetro de grande importância, já que tem uma estreita relação com o preço de venda dos frutos, e os tratamentos com anelamento anteciparam

TABELA 2 - Percentagem de floração por orientações ou quadrantes, em dois anos de avaliação, e comprimento de inflorescências, em árvores de lichia 'Bengal'. Taquaritinga-SP.

\begin{tabular}{|c|c|c|c|c|}
\hline \multirow[b]{2}{*}{ Orientações } & \multicolumn{2}{|c|}{ Percentagem de floração por quadrante } & \multicolumn{2}{|c|}{ Comprimento de inflorescência } \\
\hline & $\%$ em 2003 & $\%$ em 2004 & Terminal $(\mathrm{cm})$ & Subterminal (cm) \\
\hline Sudoeste & $47,61 \mathrm{a}$ & $56,32 \mathrm{a}$ & $24,94 \mathrm{a}$ & $19,52 \mathrm{a}$ \\
\hline Noroeste & $27,57 \mathrm{~b}$ & $60,68 \mathrm{a}$ & $25,42 \mathrm{a}$ & 20,76 a \\
\hline DMS (5 \%) & 10,13 & 12,57 & 2,36 & 2,80 \\
\hline C.V. (\%) & 32,26 & 28,69 & 12,44 & 18,44 \\
\hline
\end{tabular}

Médias seguidas da mesma letra, na coluna, não diferem entre si, pelo teste de Tukey, a $5 \%$ de probabilidade 
TABELA 3 - Percentagem de floração total por árvore, em dois anos de avaliação, e comprimento de inflorescências, em árvores de lichia 'Bengal'. Taquaritinga-SP.

\begin{tabular}{lcccc}
\hline & Percentagem de floração por árvore & \multicolumn{2}{c}{ Comprimento de inflorescência } \\
\cline { 2 - 5 } Tratamentos & \% em 2003 & \% em 2004 & Terminal (cm) & Subterminal (cm) \\
\hline Anelamento ramos principais & $59,00 \mathrm{a}$ & $80,95 \mathrm{a}$ & $26,22 \mathrm{a}$ & $21,28 \mathrm{a}$ \\
Anelamento ramos 4 cm & $51,00 \mathrm{ab}$ & $48,40 \mathrm{ab}$ & $25,42 \mathrm{a}$ & $18,90 \mathrm{a}$ \\
Anelamento ramos $6 \mathrm{~cm}$ & $46,00 \mathrm{ab}$ & $63,75 \mathrm{ab}$ & $26,99 \mathrm{a}$ & $20,78 \mathrm{a}$ \\
Testemunha & $33,20 \mathrm{bc}$ & $67,30 \mathrm{a}$ & $25,36 \mathrm{a}$ & $22,27 \mathrm{a}$ \\
Anelamento ramos $2 \mathrm{~cm}$ & $21,40 \mathrm{c}$ & $30,70 \mathrm{~b}$ & $23,08 \mathrm{a}$ & $18,26 \mathrm{a}$ \\
\hline DMS (5\%) & 19,99 & 35,44 & 18,58 & 5,17 \\
\hline C.V. (\%) & 24,51 & 31,44 & & 13,21 \\
\hline
\end{tabular}

Médias seguidas da mesma letra, na coluna, não diferem entre si, pelo teste de Tukey, a 5\% de probabilidade

TABELA 4 - Médias de frutos fixados por inflorescências, época de colheita e rendimento estimado por árvore de lichia 'Bengal'. Taquaritinga-SP, dezembro de 2003.

\begin{tabular}{lccc}
\hline Tratamentos & Frutos por inflorescência & Época de colheita & Rendimento estimado (kg / árvore) \\
\hline Anelamento ramos principais & $21,20 \mathrm{a}$ & $1^{\mathrm{a}}$ semana/ Dez. & 103,40 \\
Anelamento ramos 4 cm & $19,00 \mathrm{a}$ & $3^{\mathrm{a}}$ semana/ Dez. & 52,73 \\
Anelamento ramos $6 \mathrm{~cm}$ & $21,60 \mathrm{a}$ & $2^{\mathrm{a}}$ semana/ Dez. & 47,56 \\
Testemunha & $14,90 \mathrm{a}$ & $4^{\mathrm{a}}$ semana/ Dez. & 34,32 \\
Anelamento ramos 2 cm & $20,00 \mathrm{a}$ & $3^{\mathrm{a}}$ semana/ Dez. & 22,12 \\
\hline DMS $(5 \%)$ & 10,69 & - & - \\
\hline C.V. $(\%)$ & 28,70 & - & - \\
\hline
\end{tabular}

Médias seguidas da mesma letra,na coluna, não diferem entre si, pelo teste de Tukey, a $5 \%$ de probabilidade.

TABELA 5 - Características físicas e sólidos solúveis totais (SST) de frutos de lichieiras, com anelamento em ramos de diferente diâmetro. TaquaritingaSP, dezembro de 2003.

\begin{tabular}{lcccc}
\hline Tratamentos & Massa $(\mathbf{g})$ & Ø Longitudinal (mm) & Ø Equatorial (mm) & S.S.T. $\left({ }^{\circ} \mathbf{B r i x}\right)$ \\
\hline Anelamento ramos principais & $22,07 \mathrm{a}$ & $38,97 \mathrm{a}$ & $33,06 \mathrm{a}$ & $17,75 \mathrm{~b}$ \\
Anelamento ramos 4 cm & $22,00 \mathrm{a}$ & $38,85 \mathrm{a}$ & $33,26 \mathrm{a}$ & $32,79 \mathrm{a}$ \\
Anelamento ramos 6 cm & $20,72 \mathrm{a}$ & $39,45 \mathrm{a}$ & $32,23 \mathrm{a}$ & $18,42 \mathrm{ab}$ \\
Testemunha & $20,80 \mathrm{a}$ & $37,70 \mathrm{a}$ & $32,19 \mathrm{a}$ & $19,06 \mathrm{~b}$ \\
Anelamento ramos 2 cm & $20,37 \mathrm{a}$ & $36,77 \mathrm{a}$ & $\mathrm{a}$ & 1,86 \\
\hline DMS (5\%) & 3,31 & 2,99 & 2,95 & 1,07 \\
\hline C.V. $(\%)$ & 8,07 & 4,04 & $\mathrm{ab}$ & 3,02 \\
\hline
\end{tabular}

Médias seguidas da mesma letra,na coluna, não diferem entre si, pelo teste de Tukey, a 5\% de probabilidade.

significativamente a colheita, apresentando uma diferença de até três semanas entre o tratamento de ramos principais e a testemunha. A explicação desta diferença pode estar no acúmulo de fotoassimilados na parte aérea, como foi reportado por Li \& Xiao (2001). Na época em que o experimento foi conduzido, essa diferença em época de colheita resultou num incremento para o produtor de $\mathrm{R} \$ 5,00$ por $\mathrm{kg}$ de fruto vendido. Em função da produção obtida, nos ramos anelados, estimouse o rendimento total da planta, o que, quando comparado com o da testemunha, revelou diferenças marcantes entre os tratamentos, sendo que, nas plantas com anelamento, nos ramos principais, obteve-se um rendimento $200 \%$ maior que o da testemunha, seguido pelos tratamentos com anelamento de ramos de 4 e $6 \mathrm{~cm}$ de diâmetro, respectivamente.

Para as características físicas dos frutos, não se observou diferença estatística entre os tratamentos (Tabela 5), a massa do fruto apresentou uma variação de 20,37 a 22,07 g, os diâmetros, longitudinal de 36,77 a 39,45 mm e equatorial de 32,19 a 33,26 mm. Estas observações são semelhantes às citadas por Menzel \& Kernot (2002), para frutos de lichia 'Bengal', o que significa que o anelamento de ramos não altera as características físicas dos frutos. Para o teor de sólidos solúveis totais, houve diferença estatística significativa a favor da testemunha, que pode estar relacionada ao número de frutos fixados por árvore e por a testemunha ter menor frutificação. Quanto menor a quantidade de frutos, maior a disponibilidade de reservas para cada um deles e, portanto, $\mathrm{o}$ teor de sólidos solúveis totais pode ser maior, além de que os frutos da testemunha foram colhidos de uma a três semanas mais tarde do que nas plantas aneladas, por o que permanecem mais tempo nas plantas.

\section{CONCLUSÕES}

Constatou-se que o anelamento em ramos principais aumenta o florescimento sem alterar o desenvolvimento das inflorescências. Não modifica o vingamento de frutos, mas, com o aumento na floração, melhora o rendimento por árvore, com antecipação significativa da colheita. As características físicas dos frutos não são alteradas pelo anelamento.

\section{AGRADECIMENTOS}

Ao Conselho Nacional de Ciência e Tecnologia (CONACYT) e Colégio de Postgraduados, do México, pelo apoio financeiro para a realização do doutorado, e à Fazenda Santo Antônio, de TaquaritingaSP, pelas facilidades para realizar os experimentos.

\section{REFERÊNCIAS}

CARVALHO, C.M.; SALOMÃO, C.CH. Cultura da lichieira. Viçosa: Universidade Federal de Viçosa. 2000.38p. (Boletim de extensão, 43)

GALAN S.V.; MENINI U. G. El litchi y su cultivo. Foma: FAO, Producción y Protección Vegetal. 1987. 205p. (Paper, 83)

GHOSH, S.P. Word trade in litchi: past, present and future. Acta Horticulturae, Wageningen, v. 558, p. 23-30, 2001.

HUANG, X. Production of sapindaceae fruits in China development and challenges. In: SEMINÁRIO INTERNACIONAL DE LICHIA NO BRASIL, Limeira-SP. Brasil. 2004. 
KAWATI, R. O crescimento das culturas de lichia e carambola no Brasil. In: SIMPÓSIO BRASILEIRO DE LICHIA E CARAMBOLA, 1., 2004, Jaboticabal-SP. Brasil.

LI, CH.; XIAO, Y. Girdling increases yield of 'Nuomici' litchi. Acta Horticulturae, Wageningen, v. 558, p. 233-235, 2001.

LI, Y.C.; DAVENPORT, T.L.; RAO, R.; ZHENG, Q. Nitrogen, flowering and production of lychee in Florida. Acta Horticulturae, Wageningen, v. 558, p. 221-224, 2001.
MENZEL, C.; SIMPSON, D.R. Temperatures above $20^{\circ} \mathrm{C}$ reduce flowering in lychee (Litchi chinensis Sonn.). Journal of Horticultural Science, Ashford, v. 70, n. 6, p. 981-987, 1995.

MENZEL, C. The physiology of growth and cropping in lychee. Acta Horticulturae, Wageningen, v. 558, p. 175-184, 2001.

MENZEL, C.; KERNOT, I. Lychee information kit. Nambour: Department of Primary Industries, 2002. 260p. (Series AGRILINK)

YAMANISHI, O.K.; MACHADO, J.A.; KAWATI, R. Overview of litchi production in São Paulo state Brasil. Acta Horticulturae, Wageningen, v. 558, p. 59-62, 2001. 